\title{
Big city blues: health disparities within the world's largest urban centres
}

Previously published at www.cmaj.ca

$\mathrm{T}$ he enormity of the challenge - and the gulf between rhetoric and reality - was immediately evident.

A well-heeled British delegate stepped up to the microphone at the World Health Summit in Berlin, Germany, and chided Dr. Hans Dohmann, municipal secretary of health for the city of Rio de Janeiro, Brazil, for having taken more than a decade to begin implementing his federal government's dictum to expand primary health care to all citizens.

Dohmann bristled at the suggestion that Rio had been lax in delivering primary care in its slums, where only $3 \%$ of denizens had ready access to a doctor, health worker or health facility.

It's one thing to implement the "very romantic" notion that a "gaucho with a stethoscope" can just ride into a rural area or a small city and cure everyone's ills, Dohmann said. But it's another thing altogether to build the health infrastructure and hire the health workers needed to provide primary and dental care for the more than one million people living in the city's often-violent hillside slums, while also improving care for its remaining 11.6 million residents.

"It takes time," Dohmann stressed, expressing pride that primary health and dental care will be extended to $16 \%$ of slum residents by the end of this year and that $30 \%$ will have access by 2012 .

Therein lies an enormous dilemma for the world's so-called "megacities," (which are typically defined as metropolitan areas with a total population in excess of 10 million people): how to provide health care for the everincreasing number of poor and the marginalized people in the world who are born, or are flocking, to oftenunstructured urban environments. It's not as onerous a task for megacities in the wealthy industrialized world, such as Tokyo, Japan (33 million residents) and New York City, New York (about

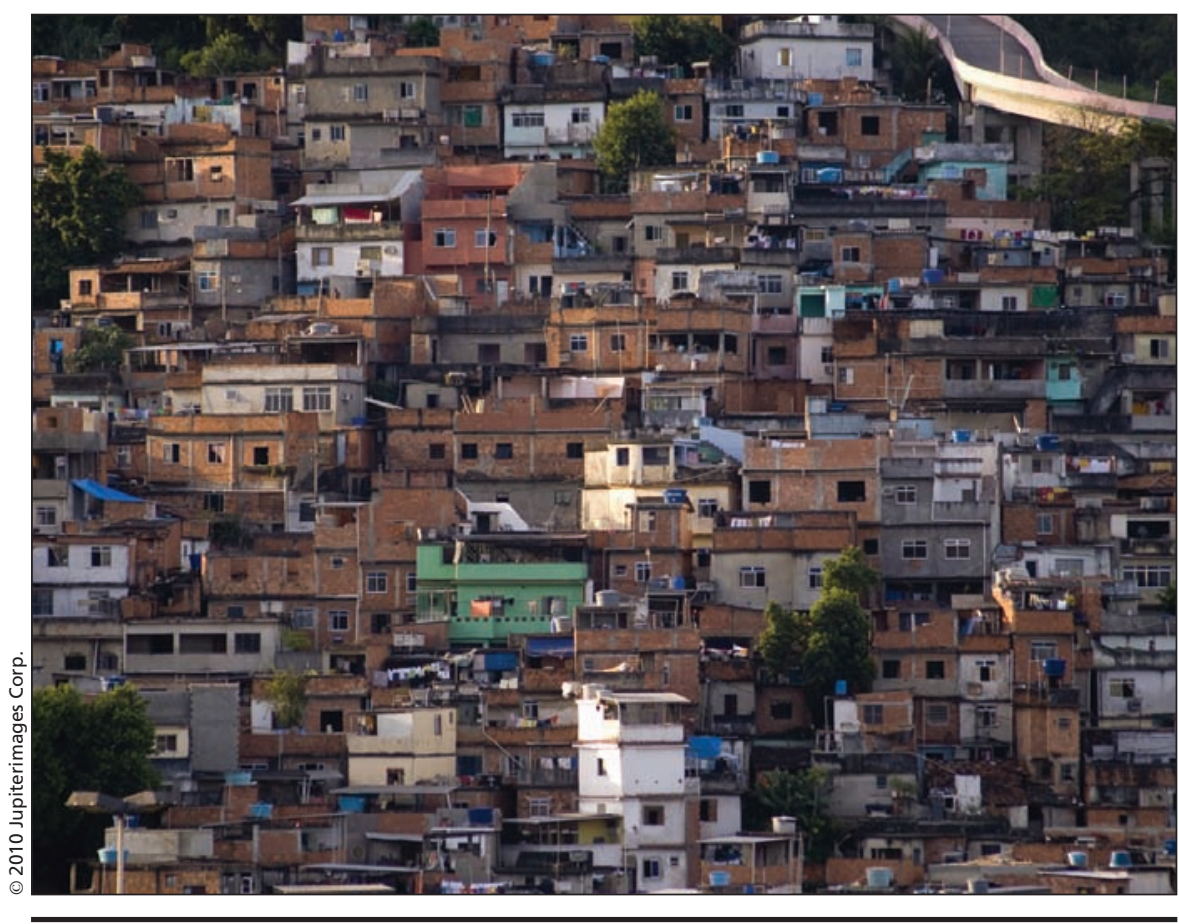

It's no small task to build the health infrastructure and hire the health workers needed to provide primary and dental care for the more than one million people living in the hillside slums of Rio de Janeiro, Brazil, according to Dr. Hans Dohmann, the city's municipal secretary of health.

18 million residents), as it is for those in developing or emerging countries.

Dohmann says Rio's challenge was nothing short of "immense," and ranged from finding new homes for slum tenants who were displaced by the construction of new health facilities to finding health care workers willing to toil in the dangerous slums.

"There's a long list of difficulties but I think the major ones were the cultural aspects (attitudes) of professionals, and from the communities - to understand the new model, and how to work in this model. The other was the bureaucracy. We were fighting a lot with the bureaucracy to implement this plan."

The plan basically involved divvyingup the city into "micro-regions," in which primary health care would be contracted from, and managed by, a private not-for-profit organization. The goal was to create a walk-in clinic or family health unit for every 30000 residents and a "municipal reference hospital" for every 150000 residents.
Dohmann earlier told the summit session that because of the cultural and social conditions of the slums, there was a need to hire a community liaison person to convince residents to use facilities and "take pride in their health." So it was decided that a "health agent" had to be hired for each of the local clinics. Recruiting those agents, along with pediatricians willing to venture into the slums, has been the biggest staffing obstacle, he says.

Then there was the cost. Over a three year period, "to implement the program we're spending about 1.5 billion reals (\$908.2 million) per year," he says. "At the beginning, people didn't believe that it was possible. Now they're beginning to believe."

Rio's challenges are not unique, delegates to the "Megacities: Opportunities and Challenges for Health" session were told.

The health disparities and inequities within segments of cities are often enormous, said Ricky Burdett, director 
of LSE Cities at the London School of Economics in the United Kingdom. "About $33 \%$ of urban dwellers (within the world's megacities) live in slums."

In some megacities, such as Mumbai, India, slum dwellers were moved into new housing, but within months, the buildings became all but unlivable, as residents were unable to pay for electricity and municipal services such as garbage collection were nonexistent, Burdett said, displaying pictures of apartment blocks strewn with waste. "Inequality is actually being built in stone around us," he said.

Health problems in megacities are also magnified by the increased amount of transportation that is required to move their populations, which results in a higher incidence of traffic injuries and deaths, and a higher incidence of stress and mental disease that are the products of hours spent in the daily commute, Burdett added.

Residents are also in a position to be more exposed to infectious or sexually transmitted diseases, and more likely to be prone to drug or alcohol abuse, he said.

Among numerous other considerations are the nature of the government and the socio-cultural conditions within a city, said Dr. Timothy Evans, dean of the school of public health at BRAC University in Dhaka, Bangladesh. Some parts of some cities in Pakistan, for example, are either in "the hands of the army, or in the hands of squatters," he said.

Other panelists, such as Victor Rodwin, director of the New York-based World Cities Project, argued that cities must improve their planning to prevent adverse health effects by ensuring that adequate and inexpensive modes of public transportation (such as bike paths), parks and health facilities are available.

Yet, the irony is that for some residents of slums, megacity life can be healthier than it is for those living in rural areas, primarily because residents are more likely to have access to health care, or are more able to afford that care, Burdett added. "A kid in Mexico City makes more money selling cigarettes in a day than he would working in agriculture." - Wayne Kondro, CMAJ

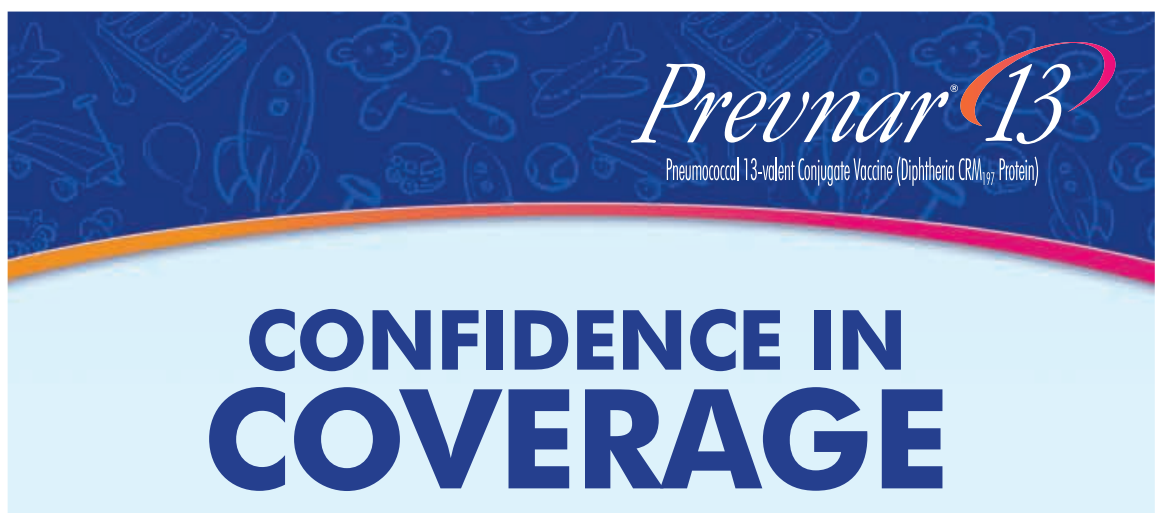

\begin{tabular}{l|l|l|l|l|l|l|}
4 & $6 \mathrm{~B}$ & $9 \mathrm{~V}$ & 14 & $18 \mathrm{C}$ & $19 \mathrm{~F}$ & $23 \mathrm{~F}$ \\
\hline
\end{tabular}

seven serotypes contained in Prevnar (7-valent)
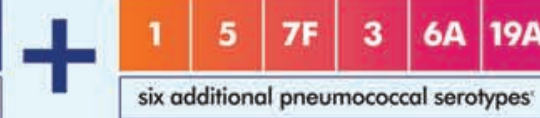

six additional pneumococcal serotypes

\section{Prevnar" 13 helps protect children against pneumococcal disease caused by the seven serotypes contained in Prevnar (7-valent), plus six additional serotypes $(1,3,5,6 \mathrm{~A}, 7 \mathrm{~F}, 19 \mathrm{~A})$.}

- These six additional serotypes caused up to $48 \%$ of residual IPD in 2007 in children $<5$ years.'

- Serotypes 19A, 6A and 3 have emerged as the predominant pneumococcal serotypes causing IPD in Canadian children, accounting for approximately 1/3 of residual IPD in 2007 in children $<5$ years."

- 19A is increasingly likely to be resistant to commonly used first-line antibiotics.

+ Data from Canadian surveillance system: Immunization Monitoring Program, Active (IMPACT).

Very common ( $\geq 10 \%)$ and common ( $\geq 1 \%$ and $<10 \%)$ adverse events associated with Prevnar" 13 include fever, any injection-site erythema, induration/swelling or pain/tenderness, decreased appetite, irritability, drowsiness, increased sleep, restless sleep/decreased sleep, diarrhea, vomiting, rash.

Prevnar 13 is contraindicated in patients who are hypersensitive to any part of the vaccine including diphtheria toxoid.

As with all injectable vaccines, appropriate medical treatment and supervision must always be readily available in case of a rare anaphylactic event following administration of the vaccine.

Minor illnesses, such as mild respiratory infection, with or without low-grade fever, are not generally contraindications to vaccination. The decision to administer or delay vaccination because of a current or recent febrile illness depends largely on the severity of the symptoms and their etiology. The administration of Prevnar 13 should be postponed in subjects suffering from acute severe febrile illness.

As with any intramuscular injection, Prevnar 13 should be given with caution to infants or children with thrombocytopenia or any coagulation disorder, or to those receiving anticoagulant therapy.

Prevnar" 13 will not protect against Streptococcus pneumoniae serotypes not included in the vaccine. Prevnar 13 will not protect against Streptococcus pneumoniae serotypes not included in the vaccine. media. This vaccine is not intended to be used for the treatment of active infection.

As with any vaccine, Prevnar" 13 may not protect all individuals receiving the vaccine from pneumococcal disease.

The use of the pneumococcal conjugate vaccine does not replace the use of 23 -valent pneumococcal polysaccharide vaccine (PPV23) in children $\geq 24$ months of age with sickle cell disease, asplenia, HIV infection, chronic illness, or who are otherwise immunocompromised.

Immunization with Prevnar 13 does not substitute for routine diphtheria immunization.

Safety and immunogenicity data on Prevnar 13 are not available for children in specific groups at higher risk for invasive pneumococcal disease (e.g., children with congenital or acquired splenic dysfunction, HIV infection, malignancy, nephrotic syndrome). Children in these groups may have reduced antibody response to active immunization due to impaired immune responsiveness. Vaccination in high-risk groups should be considered on an individual basis.' Product Monograph available on request.

1. Prevnar" 13 Product Monograph. Wyeth Canada, December 21, 2009. 2. Prevnar" Product Monograph, Wyeth Canada December 22, 2008. 3. Synflorix ${ }^{\mathrm{TM}}$ Product Monograph, GlaxoSmithKline, May 5, 2009

Prevnar Wyeth, owner, now a part of Pfizer Inc

Synflorix ${ }^{\mathrm{TM}}$ is a trademark of GlaxoSmithKline.

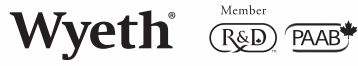

(C) 2010 Wyeth Canada
Montréal, Canada H4R 1J6

i 